\title{
Recovery of function after cortical lesions in rats: Temporal, practice, and ethanol effects
}

\author{
FRANK A. HOLLOWAY \\ University of Oklahoma Health Sciences Center, Oklahoma City, Oklahoma 73190 \\ and \\ MEREDITH A. DAVISON \\ Oklahoma College of Osteopathic Medicine, Tulsa, Oklahoma 74101
}

\begin{abstract}
Temporal, practice, and pharmacological factors influencing behavioral function were examined in male albino rats after middle cortical lesions. Cortical lesioned, sham-operated, and unoperated control groups were given eight daily training sessions in a single-arm maze after postsurgery recovery periods of 10,20 , or 30 days. On Days 9 and 10, the animals received pretest ethanol and saline injections in a counterbalanced design. The middle cortical groups showed maximal impairment (increases in errors and latencies) after the 10-day recovery period, partial improvement after the 20-day postsurgery period, and control-level performance after the 30-day postsurgery period. Ethanol injections increased errors but not latencies of the lesioned animals, which had begun training 10 days after surgery. The results suggest that the lesioned animals displayed a time-dependent recovery in which practice effects played only a minor role. Further, the results suggest that the cortically lesioned animals just at the point of recovery are hypersensitive to the debilitating effects of ethanol.
\end{abstract}

Behavioral functions lost after central nervous system (CNS) damage may recover in a time-dependent fashion (Rosner, 1970). Factors influencing recovery rate include: extent and type of lesion (Glick, 1974), time since surgery (Harrel \& Issac, 1969), interpolated practice (Kircher, Braun, Meyer, \& Meyer, 1970), and postinjury CNS changes (Glick, 1974). Pharmacological treatments also may influence the course of recovery and may interact with the CNS lesion (see Glick, 1974; Glick \& Zimmerberg, 1978). Systematic research on the interaction of drugs and CNS lesions generally has addressed three issues: the neuroanatomical locus of drug action, comparability between drug action and lesion effects, or changes in drug sensitivity after CNS lesions. The latter topic was investigated in this study.

Recent research on drug sensitivity and CNS damage most frequently employed drugs with known and relatively specific actions on neurotransmitter function (see Glick \& Zimmerberg, 1978). For example, primates or rats with frontal lesions may display either hyposensitivity or hypersensitivity to amphetamine, the effect being determined by the nature of task conditions, drug dose, extent of lesions, and/or degree of behavioral recovery (Glick \& Zimmerberg, 1978).

This research was supported in part by Public Health Service Grant 14702 from the National Institute of Mental Health. The authors wish to thank Drs. Joan A. Holloway and Oscar A. Parsons for their critical reading of the manuscript. Address reprint requests to F. A. Holloway, Department of Psychiatry and Behavioral Sciences, University of Oklahoma Health Sciences Center, P.O. Box 26901, Oklahoma City, Oklahoma 73190.
Other drugs that have less specific actions on brain neurotransmitter functions also may display interactions with CNS lesions. For example, older literature indicates that sensitivity to depressive drugs like barbituates and ethanol may be increased by decortication (Mettler \& Culler, 1934; Stavraky, 1961). Holloway and Vardiman (1979) described data suggesting that CNS lesions enhance the sensitivity of rats to the behavioral effects of ethanol. Cortical and subcortical lesions produced significant hyperactivity and impairment of two aspects of Lashley III maze acquisition performance. At the end of the 20-day maze training period, one behavioral impairment (indicated by door errors, i.e., failure to locate alley entry points) had disappeared, while the other behavioral impairment (indicated by alternation errors, i.e., failure to turn in the correct direction), along with the hyperactivity, persisted. Ethanol administered at the end of training significantly increased the number of door errors in the cortically lesioned group but not in the subcortically lesioned or control groups. Further, ethanol significantly reduced spontaneous locomotor activity in the subcortically lesioned group but not in the cortically lesioned or control groups. The improvement in maze performance could have resulted from either training or the passage of time since surgery. Finally, the ethanol/brain-damage interaction effects seemed to depend on the type of lesion, behavior examined, and the extent of improvement across time and/or training.

The purpose of the present study was to further explore behavioral recovery after middle cortical lesions 
and the interactive effects of such lesions with ethanol. Following various recovery periods, middle cortical lesioned and control rats were given training in a singlearm maze, previously shown to be sensitive both to lesion and ethanol treatments (Vardiman, 1970). The effect of ethanol on maze performance was subsequently examined.

\section{METHOD}

\section{Subjects and Experimental Design}

The subjects were 72 male Sprague-Dawley rats, weighing between 280 and $400 \mathrm{~g}$ at the beginning of the experiment. All animals were housed individually under constant light conditions and were adapted to the animal quarters for 10 days prior to surgery. Animals were randomly assigned to the following groups $(n=24$ each): middle cortical lesion $(M C)$, sham-operated controls (SC), and unoperated controls (UC). Within each of the latter groups, subgroups of eight animals were randomly assigned to one of three postsurgery periods: 10,20 , or 30 days. The "recovery" period for all UC animals began after the initial 10-day adaptation period.

\section{Surgery and Histology}

All surgery was performed under sodium pentobarbital anesthesia $(60 \mathrm{mg} / \mathrm{kg})$, with rats positioned in a Kopf stereotaxic apparatus. Bilateral cortical ablation was accomplished by gentle aspiration of exposed cortical gray matter and was restricted to the dorsal surface of the brain from .5 to $1.0 \mathrm{~mm}$ off midline to the temporal ridge. The lesion extended from bregma to a point $5 \mathrm{~mm}$ posterior to bregma. The sham-operated animals received identical surgical procedure, except that no bone was removed.

At the end of the experiment, subjects were deeply anesthetized with sodium pentobarbital and perfused with $.9 \%$ saline followed by $10 \%$ formalin solution. Planimeter measurements indicated that cortical damage in 18 of the $24 \mathrm{MC}$ rats was restricted to the designated area. Of the remaining six MC rats, two had slightly more anterior cortical damage and four had slightly more posterior cortical damage. The MC rats with irregular cortical lesions were distributed evenly among the $10-, 20-$, and 30-day postsurgery recovery subgroups and did not differ from the other MC animals on maze performance (MannWhitney U test; Siegel, 1956).

\section{Apparatus}

The simple maze, described in detail elsewhere (Vardiman, 1970), consisted of a 152-cm black wooden straight alley with black wooden goalboxes $(70.2 \mathrm{~cm}$ long) positioned at right angles to the straight alley, $46.8 \mathrm{~cm}$ from the distal end of the straight alley. Both the straight alley and the side goalboxes were $15.6 \mathrm{~cm}$ wide and had $30.5-\mathrm{cm}$ walls. Either side goalbox could be blocked off. A removable door was located $46.8 \mathrm{~cm}$ from the proximal end of the straight alley, forming the startbox. All portions of the maze were covered with hinged clear Plexiglas lids. The entire apparatus was housed in a dim, soundattenuated room.

\section{Procedure}

Ten days before maze training began, each animal was given $70 \%-80 \%$ of the amount of food consumed during the 10-day adaptation period. All rats were trained and tested at $80 \%$ of their average body weight, determined during the initial 10-day adaptation period. Handling, weighing, and testing were done at the same time each day for a given rat and only one experimenter tested a given rat. All training and testing occurred be tween the hours of 9:00 a.m. and 3:00 p.m.

For one half of the animals in each subgroup, the goalbox located on the right side of the straight alley was baited with food reinforcement; for the remaining rats in each subgroup, the goalbox located on the left side was baited with food. The opposite (nonbaited) goalbox was blocked off. On a given trial each rat was placed in the maze startbox. Once the rat oriented toward the door, the door was raised, allowing the animal to run down the straight alley and eventually enter the baited goalbox. The subject was allowed $30-\mathrm{sec}$ access to the wet lab chow located at the distal end of the goalbox. The rat was then removed from the maze, placed in its holding cage for $60 \mathrm{sec}$, and given a second trial. All animals were routinely fed $30 \mathrm{~min}$ following the daily maze sessions.

All subjects received two trials per day for 10 consecutive days. The first 8 days were acquisition training. On Days 9 and 10 , half the subjects in each subgroup $(n=4)$ received ethanol injections on Day 9 and saline injections on Day 10; the remaining half of the subjects received ethanol-saline injections in the reverse order. All injections were administered intraperitoneally $15 \mathrm{~min}$ prior to the daily session. The ethanol injection dose was $1.0 \mathrm{~g}$ ethanol $(10 \% \mathrm{w} / \mathrm{v})$ per kilogram of body weight. The amount of normal saline injected was a volume equivalent to that injected on the ethanol day. The ethanol injections might be expected to produce blood alcohol levels of 69 and $58 \mathrm{mg} / \mathrm{dl}$ at 15 and $25 \mathrm{~min}$ postinjection (interpolated values from Holloway \& Wansley, 1973).

\section{Performance Measures and Statistical Analyses}

Maze performance was measured by the latency to enter the goalbox after the raising of the startbox door and by the number of goalbox entry errors. The latter error was similar to the "door error" measure used by Holloway and Vardiman (1979). An entry error was recorded when the subject passed the goalbox opening in either direction by at least two thirds of its body length. During acquisition, the latency and error measures were significantly correlated (Pearson $\mathrm{r}=.71, \mathrm{df}=70, \mathrm{p}<.01$ ). For completeness, analyses of variance on both performance measures were performed. The acquisition analysis of variance was a three-way design involving groups and days since surgery, with replication across trial blocks (each trial block consisted of four trials, i.e., data from two daily training sessions). The effects of ethanol on performance were analyzed by a two-way analysis of variance (groups by days since surgery) performed on saline-day minus ethanol-day difference scores.

\section{RESULTS}

\section{Acquisition Performance}

The error data are presented in Figure 1. Analysis of variance on the error measure revealed significant differences among the MC, $\mathrm{SC}$, and UC groups $[\mathrm{F}(2,63)=7.46$, $\mathrm{p}<.01]$ and a significant Groups by Days Postsurgery interaction $[F(4,63)=2.92, p<.01]$. Simple effects analysis on the latter interaction showed significant group differences 10 days postsurgery $[\mathrm{F}(2,63)=11.65$, $\mathrm{p}<.01]$ and 20 days postsurgery $[\mathrm{F}(2,63)=3.17$, $\mathrm{p}<.05]$, but not 30 days postsurgery. The MC group displayed significantly more overall errors and more errors 10 days postsurgery than either the SC or UC groups (Newman-Keuls test, $p<.01$ ). At 20 days postsurgery the MC group only had significantly more errors than the UC group $(\mathrm{p}<.01)$. Further, the MC groups beginning training 20 or 30 days postsurgery made fewer errors than the $\mathrm{MC}$ group beginning training 10 days postsurgery $(\mathrm{p}<.01)$. The analysis of variance also indicated a significant trial block effect $[\mathrm{F}(3,189)=$ $19.58, \mathrm{p}<.01]$ and a Trial Block by Groups inter- 

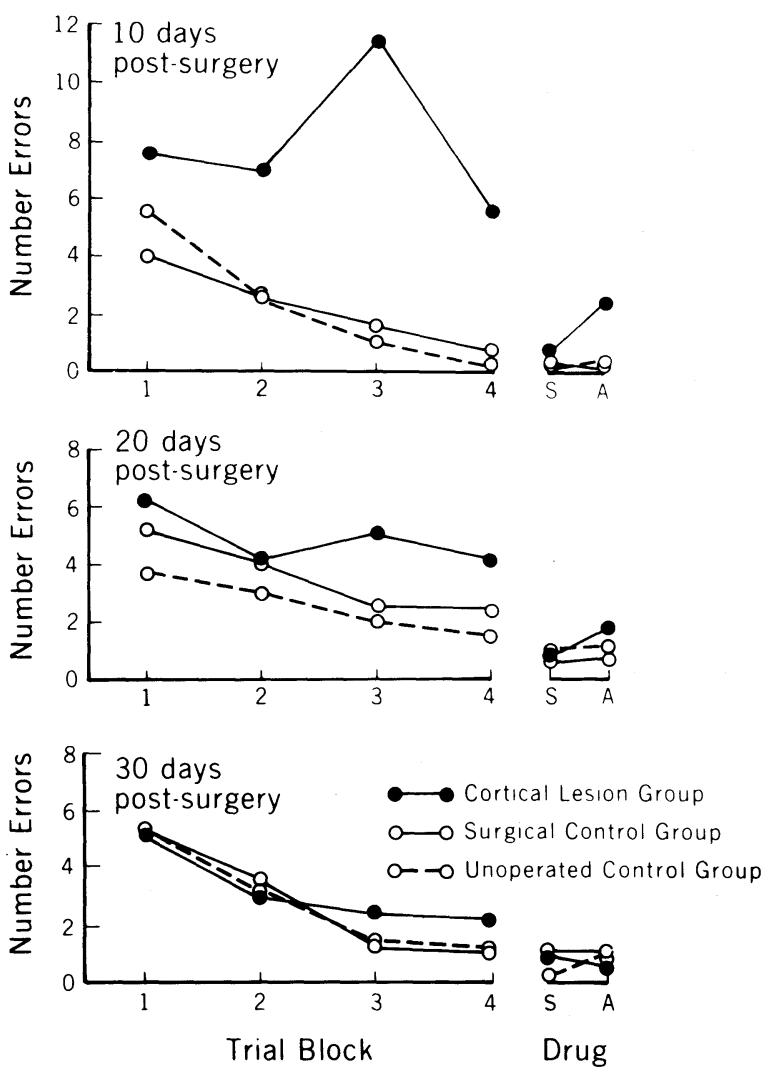

Figure 1. Mean number of maze errors per trial for cortical lesioned, sham-operated control, and unoperated control groups given 10-, 20-, or 30-day postsurgery recovery periods. Data are presented for acquisition trial blocks (four trials/block) and for saline and ethanol injection trial blocks (two trials/block).

action $[F(6,189)=3.20, p<.01]$. Simple effect analysis indicated significant group differences on Trial Blocks 2 , 3 , and 4 at 10 days postsurgery (ps $<.05$ ). Both control groups displayed significant linear trends for the trial block factor 10, 20, and 30 days postsurgery (ps <.05). The MC group, however, showed a significant linear trial block trend only at the 30-day postsurgery condition $(p<.05)$. At 10 days postsurgery, the MC groups displayed significant quadratic and cubic trial block trends $(\mathrm{p}<.05)$.

The latency data are presented in Figure 2. Analysis of variance on the latency measure showed significant effects for trial block $[F(3,189)=55.63, p<.01]$, groups by trial block $[\mathrm{F}(6,189)=3.04, \mathrm{p}<.01]$, and the Groups by Days Postsurgery by Trial Block interaction $[F(12,189)=1.91, p<.05]$. Simple effect analysis revealed group differences only at the 10-day postsurgery condition and then only at Trial Blocks 1 and 3 (all ps $<.01$ ). All groups at all days-postsurgery periods showed significant linear decreases in latency across trial blocks (all ps $<.01$ ).

\section{Effects of Ethanol on Maze Performance}

The error and latency measure data for the ethanol and saline days can be seen in Figures 1 and 2, respec- tively. There were no significant differences between those animals receiving the ethanol-saline vs. the salineethanol injection sequences. The analysis of variance on the latency measure showed no significant main or interaction effects. However, the error difference scores did differentiate the groups $[F(2,63)=5.84, p<.01]$. Simple effect analysis indicated the group difference was significant only for the 10-day postsurgery condition $[F(2,63)=4.52, p<.05]$. Further, the NewmanKeuls multiple-comparison test indicated that for the 10-day postsurgery condition the MC groups made significantly more errors on the ethanol day (relative to the saline day) than did either the SC or UC groups $(\mathrm{p}<.05)$.

\section{DISCUSSION}

The results indicate that middle cortical lesions significantly impaired maze performance (indicated by both error and latency
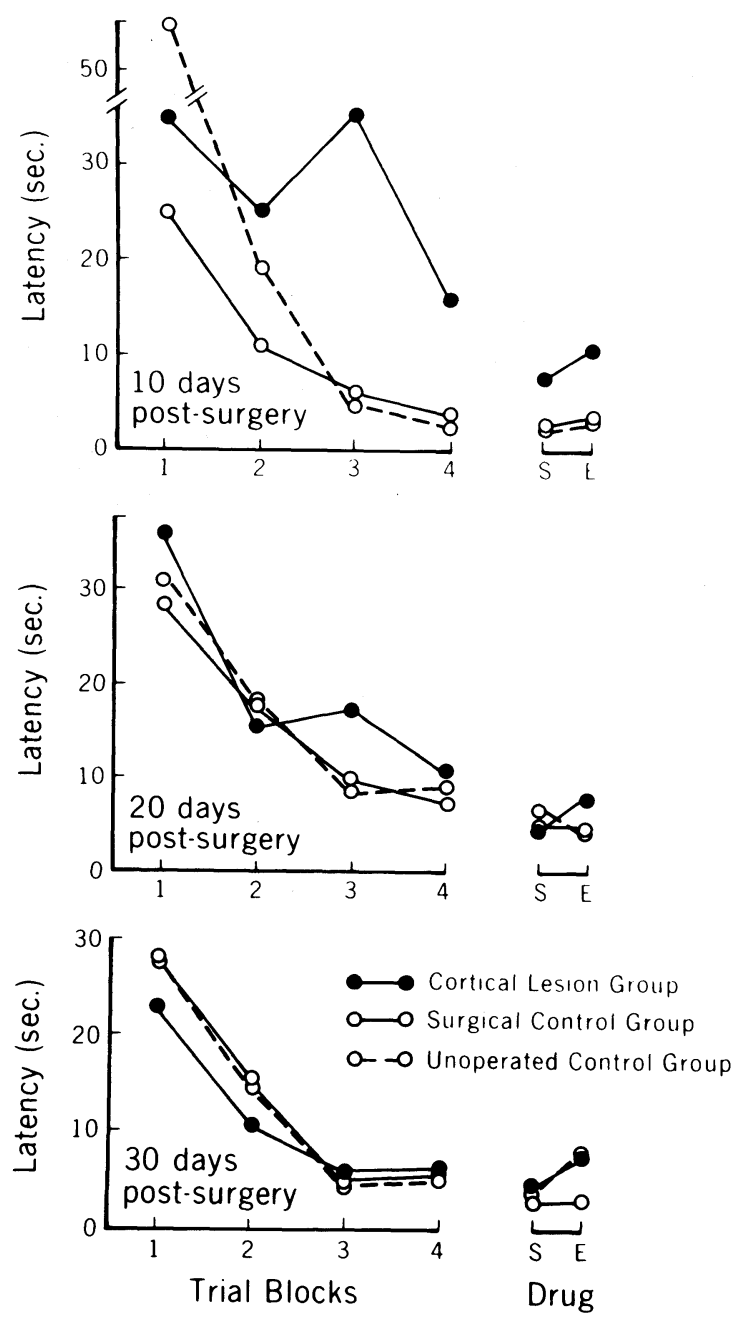

Figure 2. Mean latency per trial to reach the goalbox for cortical lesioned, sham-operated control, and unoperated control groups given 10-, 20-, or 30-day postsurgery recovery periods. Data are presented for acquisition trial blocks (four trials/block) and for saline and ethanol injection trial blocks (two trials/block). 
measures) but that the lesioned animals showed a time-dependent recovery. The behavioral deficits were maximal in the group tested between 10 and 20 days postsurgery. The error measure indicated a mild impairment of maze performance in the group tested between 20 and 30 days postsurgery, but this group performed significantly better than the 10-day postsurgery group. No group differences in error scores were noted for the 30-day postsurgery condition. The latency measure showed no significant group differences for either the 20 - or 30-day postsurgery conditions. Finally, ethanol injections produced a significant increase in errors made by the MC-rats that began their training 10 days postsurgery.

The present data suggest that time since surgery per se, and not the training procedure, was the major factor in the improvement in the MC group's maze performance. However, the role of practice in the MC groups' improved maze performance may be different for the error and latency measures. The latency data indicated the MC groups displayed significant linear decreases across trial blocks at all postsurgery intervals, while the error data indicated a significant linear decline in the MC group's errors across trial blocks only at the 30-day postsurgery condition. The data further indicated that significant group differences on the error score measure still existed on the final acquisition trial block of the 10-day postsurgery condition but not on the first trial block of the 20-day postsurgery condition (nor on any later trial block). Such data seems to support a primary role for passage of time per se in the reduction of the MC group's error scores. However, there are no significant group latency differences on the final acquisition trial block of the 10-day postsurgery condition. Thus, for the latency measure it is impossible to tell whether the MC group's improvement to control levels by the final trial block of the 10-day postsurgery condition was due to training or to mere passage of time.

The debilitating effects of ethanol on the MC group's maze performance 10 days postsurgery is consistent with the notion that the lesion enhanced the animal's sensitivity to ethanol. Presumably, the control groups also would have shown ethanolinduced increases in error scores at higher doses of the drug. Increased sensitivity to ethanol has been reported in only a few studies (Mettler \& Culler, 1934; Holloway \& Vardiman, 1979). In the present experiment, ethanol was administered at approximately the time maze performance was improving to control levels (i.e., Day 10 postsurgery). The ethanol-induced increase in door errors in the Holloway and Vardiman (1979) study occurred in cortically lesioned rats that had just recovered from their lesion-produced impairment (i.e., about Day 35 postsurgery). The greater maze complexity in the latter study probably contributed to the longer recovery time. Glick and Zimmerberg (1978) suggested that increased sensitivity to drugs and recovery of behavioral function may display parallel changes and that both effects may depend on some CNS-mediating process, such as postsynaptic supersensitivity. The latter supersensitivity model for drug-brain lesion interactions seems to apply more appropriately to studies using drugs that have more or less specific neurotransmitter action (e.g., amphetamine). Although the precise nature of ethanol's effects on specific neurotransmitter functions is uncertain, acetaldehyde or aldehyde-condensation products derived from biogenic amines may well have specific effects on neurotransmitter systems (Myers, 1978).

\section{REFERENCES}

Glick, S. D. Changes in drug sensitivity and mechanism of functional recovery after brain damage. In D. G. Stein, J. J. Rosen, \& N. Butters (Eds.), Plasticity and recovery of function in the central nervous system. New York: Academic Press, 1974.

Glick, S. D., \& Zimme RBe RG, B. Pharmacological modification of brain lesion syndromes. In S. Finger (Ed.), Recovery from brain damage: Research and theory. New York: Plenum, 1978.

HARREL, N., \& IsaAC, W. Frontal lesions and illumination effects upon the activity of the albino rat. Physiology \& Behavior, $1969,4,477-478$.

Holloway, F. A., \& Vardiman, D. R. Interactive effects of ethanol and central nervous system lesions on animal behavior. Alcohol Technical Reports, 1979, in press.

Holloway, F. A., \& Wansley, R. A. Factors governing the vulnerability of DRL operant performance to the effects of ethanol. Psychopharmacologia, 1973, 28, 351-362.

Kircher, K. A., Braun, J. J., Meyer, D. R., \& Meyer, P. M. Equivalence of simultaneous and successive neocortical ablations in production of impairments of retention of black-white habits in rats. Journal of Comparative and Physiological Psychology, 1970, 71, 420-425.

Mettler, F. A., \& Culler, E. Action of drugs on the chronic decorticated preparation. Journal of Pharmacology and Experimental Therapeutics, 1934, 52, 366-377.

MYe rs, R. D. Psychopharmacology of alcohol. Annual Review of Psychology, 1978, 18, 125-144.

Rosner, B. S. Brain function. Annual Review of Psychology, 1970, 21, 555-594.

Siegel, S. Nonparametric statistics for the behavioral sciences. New York: McGraw-Hill, 1956.

Stavraky, G. W. Supersensitivity following lesions of the nervous system. Toronto: University of Toronto Press, 1961.

VARDIMAN, D. R. A reexamination of localization of function in the rat neocortex. Unpublished doctoral dissertation, University of Oklahoma, 1970.

(Received for publication June 4, 1979.) 